\title{
Electronic Waste Recycling Mode and Control Measures in China Based on PEST and SWOT
}

\author{
Linsheng Wang† and Wei Yang \\ College of Electronic Information Engineering, Henan Polytechnic Institute, Nanyang 473000, China \\ †Corresponding author: Linsheng Wang; wanglinsheng_317@163.com
}

Nat. Env. \& Poll. Tech.

Website: www.neptjournal.com

Received: 28-09-2020

Revised: $18-11-2020$

Accepted: 15-12-2020

\section{Key Words:}

E-waste

Recycling mode

Control measures

PEST

SWOT

\begin{abstract}
The service life of electronic (e-) products is decreasing gradually due to the continuous improvement of manufacturing technologies and increasing prices and performance of these products, thereby accelerating the growth of e-waste. Only a small proportion of e-waste is disposed of according to standards in China. Due to a contradiction between high output and low disposal, environmental pollution and resource waste caused by e-waste intensify daily. To further analyze the e-waste recycling mode from a macroscopic level and thereby propose specific control measures, we first reviewed studies on e-waste recycling modes and control measures in foreign developed countries. Second, the e-waste recycling mode in China was analysed through political, economic, social and technological (PEST) and strengths, weaknesses, opportunities and threats (SWOT) models in combination with practical situations in China. Finally, e-waste control measures were proposed from various perspectives. Results show that the ambiguous definition of responsibilities for different e-waste disposal subjects in China has led to serious environmental pollution. This pollution, the extensive waste of natural resources, and frequent occurrence of social crises are three consequences of environmental pollution caused by e-waste in China. All four factors in the PEST model have laid the foundation to accelerate e-waste recycling in the country. Environmental pollution caused by e-waste can be relieved by perfecting relevant laws and regulations for e-waste recycling and disposal; establishing and perfecting the punitive system for e-waste recycling corporate responsibility; strengthening technological support, promotion, and education on e-waste recycling; and increasing the market supervision efforts and manufacturers' consciousness of responsibility. Research conclusions can provide important references to analyze e-waste status, achievements, challenges, and existing problems in disposal as well as their causes. These factors can also propose countermeasures and suggestions in e-waste disposal in accordance with practical situations in China based on insights into the experiences of foreign countries with a typical level of development.
\end{abstract}

\section{INTRODUCTION}

With the continuous development of information and manufacturing technologies, new electronic and electrical (e-) products that possess evident advantages in price, performance, and appearance are developed to replace the old ones. Moreover, the consumption concept and behaviour of the public change and the service life of e-products is shortened with the improvement of people's living standards, thereby accelerating the growth of e-waste. In China, only a small proportion of e-waste is disposed of in a standard manner. Environmental pollution and resource waste caused by e-waste have intensified daily because of the contradiction between high output and low disposal. Although China possesses a vast territory and rich mineral resources, per-capita resource availability in the country is much lower than the world average because of China's large population base. Thus, resource shortage has become a great challenge to sustainable economic development in China.
The contradiction between resource waste and resource shortage is increasingly prominent. During classification, melting, and extraction of e-waste, a large amount of toxic substances such as lead, mercury, and cadmium are released into air, land, and water, thereby causing secondary pollution. If e-waste is not decomposed properly, then radioactive and heavy metal elements in electronics may be leaked and may cause serious environmental pollution. Moreover, traditional landfill or combustion of e-waste without remaining value may also cause damage to the soil and other environments.

With improving economic levels, increasing material demands of consumers, and the accelerating rate of urbanization in China (Fig. 1), electronic products have become popular quickly and annual consumption of electronics is increasing significantly. Meanwhile, the quantity of obsolete electronics is also growing. E-waste consists of discarded mobile phones, computers, and e-accessories in household waste. With respect to disposal 
in China, most types of e-waste recycled by non-professional enterprises are only cleaned, repaired, or assembled, and then resold to secondary markets or underdeveloped areas. Alternatively, precious metals in e-waste are extracted through low-technology and high-pollution methods, such as acid leaching and combustion. Both these disposal methods can bring serious damage to the environment. In recent years, China has achieved progress in e-waste recycling. However, faced with increasing problems in e-waste recycling, the country cannot accomplish e-waste recycling simply by depending on the government or restricting the activities of manufacturers. Thus, understanding the serious environmental pollution caused by e-waste and proposing an e-waste recycling mode that effectively conforms to the economic and social development status of China to address environmental pollution and ecological damage caused by e-waste.

\section{PAST STUDIES}

With the rapid economic development and continuous improvement of people's living standards, e-products have entered the consumption market quickly and e-waste has caused serious environmental pollution. Foreign developed countries have conducted many studies on e-waste recycling mode and control measures. Most of these studies have focused on theoretical aspects of extended responsibility of manufacturers, e-waste recycling and disposal system, and e-waste disposal costs and benefits, which have gained abundant research achievements. Major studies on e-waste recycling mode and control measures are introduced as follows. Liu et al. investigated progress in policies for old household appliance recycling and disposal in China and found that capital flow and logistics in old household appliance management had unique features. Specifically, nearly $60 \%$ of household appliance waste was sold to individual recyclers and finally treated illegally, which brought serious environmental pollution (Liu et al. 2006). Allenby et al. conducted a comparative study on e-waste recycling management institutions and systems in Japan, Europe, Taiwan, Korea, and other countries and regions; they concluded that a relevant incentive system had to be established based on laws to solve e-waste recycling problems in the United States (Allenby et al. 2008). Lu et al. discussed China's e-waste recycling management system thoroughly, finding that legal e-waste recycling and disposal enterprises were unable to compete with ubiquitous illegal enterprises if they failed to lower recycling costs through all means (Lu et al. 2008). Cheung et al. investigated Guiyu County, China, a village witnessing intensive e-waste disposal. Recycling of printed circuit boards (PCBs) in Guiyu County might cause considerable risks to the environment and human health. According to research results, recycling lead and copper in PCBs could cause serious health risks to local workers and residents, especially children (Cheung et al. 2008). Ru et al. believed that the quantity of e-waste was increasing quickly in China; however, China had neither established a corresponding recycling and disposal system nor provided appropriate administrative supervision. The researchers also pointed out several challenges encountered in the implementation of new relevant laws and regulations and proposed feasible suggestions ( $\mathrm{Ru}$ et al. 2010). Chen et

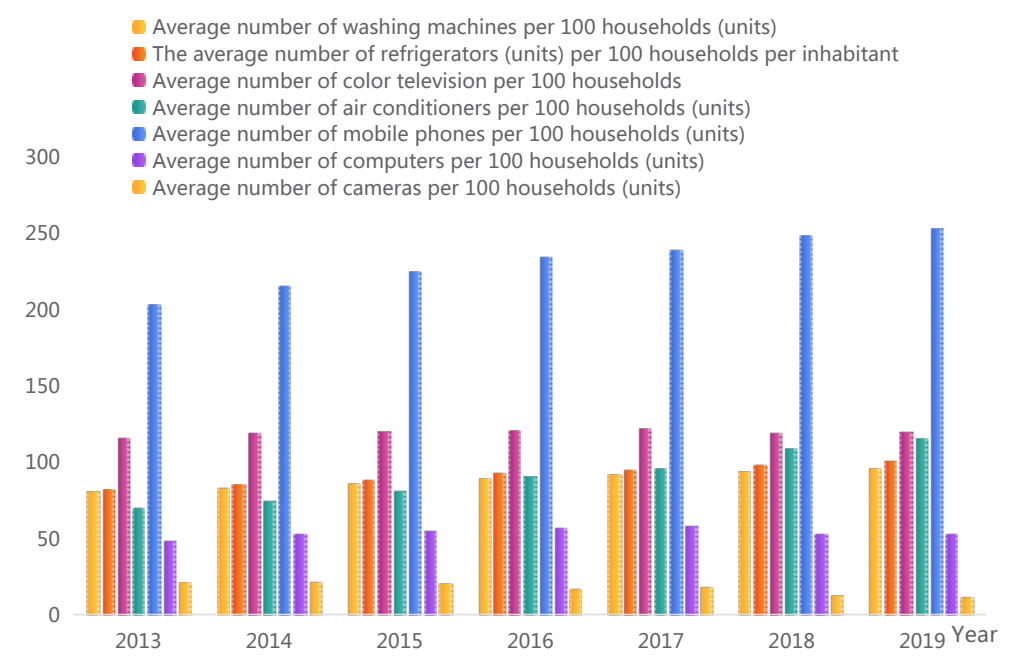

Fig. 1: Number of major electronic products owned per 100 households in China, 2013-2019. 
al. investigated e-waste recycling and contents of brominated flame retardants (BFRs) in urban dust in South China, finding serious environmental degradation in the study area (Chen et al. 2010). Halluite et al. argued that strict laws and regulations can require manufacturers to recycle products at disposal and great secondary environmental pollution related to waste storage might occur unless the affected products had stable designs and inputs simultaneously. In particular, many e-products had harmful substances that might cause serious problems if left unrecycled (Halluite et al. 2012). Atasu et al. identified the stakeholders of e-waste recycling in Washington, which included e-recyclers, consumers, management organizations, local government and system renovation providers; the researchers stated the need to formulate comprehensive policies to control e-waste pollution (Atasu et al. 2013). Covaci et al. believed that largescale e-waste has been produced worldwide due to the rapid development of the electronic industry; they investigated the existence of organo-phosphorous flame retardant and plasticizers (PFRs) in several wild insects collected from e-waste recycling areas in Guangdong Province, and found that e-waste recycling area might be an important local pollution source (Covaci et al. 2018). Tian et al. pointed out that China, the largest e-waste producer in the world, was facing a great challenge in how to control the negative effects of e-waste on the environment; they concluded that e-waste management was crucial to sustainable economic development in China. Moreover, the effects of contracts signed by the manufacturers on different retail modes were discussed (Tian et al. 2018). Chen et al. investigated several soil samples from Guiyu county, an e-waste recycling town in southeast China and concluded that e-waste recycling caused significantly serious soil damages (Chen et al. 2018). Mor et al. believed that the boom in the e-industry and acceleration of technological progress brought large number of waste electronic and electrical equipment. They investigated the production and various control means of e-waste in Chandigarh, India. According to the questionnaire survey results, only $30 \%$ of respondents were aware of e-waste and their environmental influences. The average annual output of e-waste per household in Chandigarh, India amounted to $17 \mathrm{~kg}$ and the annual output reached 4,100 t, causing severe environmental pollutions (Mor et al. 2019). Bernardes et al. discussed e-waste management based on the Australian recycling plan and found that waste computers were the sole type of equipment with sufficient internal values and could be recycled in China without any external subsidy; the researchers also analysed the importance of subsidies, rules and regulations, and supervision in e-waste recycling (Bernardes et al. 2019). Lang et al. evaluated emission reduction benefits and efficiency of e-waste recycling in China by using the directional distance function of DEA. Results showed that the total emission reduction benefits of e-waste in 29 Chinese provinces amounted to 6.34 billion yuan, and considerable potential remains in emission reduction in e-waste recycling (Lang et al. 2019). Aboelmaged studied the decisive factors in young consumers' intention toward e-waste recycling in the emerging economic environment and found that recycling habits and perceived attitudes were important influencing factors in the e-waste recycling intention of young people (Aboelmaged 2020). According to Chinese and foreign studies on e-waste disposal, foreign theories, including legislation and establishment of theoretical models, are reliable and the extended responsibility system of manufacturers has been implemented to define e-waste disposal responsibilities. Such an extended responsibility system for manufacturers shows a stage of large-scale promotion. However, the responsibilities of e-waste disposal subjects have not been defined in China due to special national conditions. Moreover, attitudes and measures implemented by the government, enterprises, social organizations, and individuals in e-waste disposal have not been determined yet. Studies on the role of different subjects in e-waste disposal are also insufficient. As a result, the status of e-waste recycling in China was analysed through a combination of political, economic, social, and technological (PEST) factors and strengths, weaknesses, opportunities, and threats (SWOT), and specific e-waste control measures were proposed. Research conclusions can provide important references to establish and make high-efficiency operation of a perfect e-waste disposal system, thereby relieving environmental pollution and resource waste.

\section{E-WASTE POLLUTION HAZARDS IN CHINA}

\section{Serious Environmental Pollution}

E-waste has complex chemical compositions. It contains a large amount of toxic and harmful substances that can pollute soil, water, animals, and plants once they are leaked to the natural environment with the direct disposal of e-waste. Abundant heavy metals and toxic chemical substances enter into animals and plants through the soil and water, which further causes death or mutation of these organisms. Human beings may suffer dysgenesis, chronic diseases, and cancer due to long-term exposure to such environments, or from consuming polluted water, animal meat, and plant products. The environmental hazards of e-waste can be classified into long-term and latent ones. The degradation rate of high-technology artefacts formed by complex processing is low in nature because the artificial synthesis of many chemical substances is beyond the capability of natural degradation. The ecological environmental deterioration 
caused by overflowing e-waste and long-term accumulation of toxins in the human body may generate multiplier effects. Furthermore, most e-waste is generated in large and mediumsized cities in China but are basically transferred to remote towns and villages with weak supervision in processing. Although this approach solves the problem of garbage siege, it can intensify the exposure to e-waste and aggravate the damage to the local environment, thereby causing greater difficulty and cost of e-waste control.

\section{Extensive Waste of Natural Resource}

At present, the e-waste disposal and processing techniques in China are underdeveloped, as manifested by the prevalence of unreasonable and non-scientific disposal techniques, small-scale processing, serious environmental pollution, and low-recovery efficiency of valuable heavy metals. Processing technologies and equipment of large enterprises are mainly imported from Western developed countries, which restricts their development due to limitations in capital and technology. China is a country with a relative resource shortage, and its long-term extensive economic development leads to relatively low utilization of resources and considerable resource waste. The resource constraint in China has intensified gradually and the contradiction with non-sustainable economic development has become increasingly prominent in recent years. Thus, promoting industrial transformation and updating and adjusting industrial structures is necessary. E-waste can be disposed of in two ways. One is through disassembly and reassembly, which involves great potential safety hazards. This type of disposal is generally performed illegally and accounts for an extremely small proportion of the total e-waste. The other is by extracting valuable resources by disassembling e-waste artificially with original tools, open burning, or direct acid leaching in open recycling areas, while the remaining parts are abandoned randomly in fields, rivers, and channels as garbage, or mixed with municipal waste. Both simple and extensive disposal methods have caused a great waste of natural resources.

\section{Frequent Occurrence of Social Crises}

Continuous renovation of e-products also causes social problems while enriching and facilitating human life. The memory function of e-products may cause information safety risks. For example, personal privacy information and even confidential information of enterprises and governments might be disclosed as a result of improper disposal of waste computer disks, memory cards of cameras, and mobile phones. On the one hand, the ecological environmental damage caused by e-waste pollution can influence the physical health and life quality of citizens to various extents, and infringe on people's right to live in a healthy environment.
On the other hand, e-waste pollution hazards have long-term potential characteristics. Thus, increasing the priority of e-waste disposal in the public policy agenda and formulating countermeasures and taking corresponding timely action is necessary. On the contrary, e-waste pollution is likely to cause a social crisis directly and bring immeasurable losses if it becomes a prominent public hazard.

\section{ANALYSIS OF E-WASTE RECYCLING MODE BASED ON PEST AND SWOT}

\section{PEST Analysis}

Political factors: China has to take the initiative in supporting the development of new recycling modes, including intelligent recycling and automatic recycling machines by exploring the "Internet + recycling" mode and path; insisting on green and sustainable development; pursuing the civilized development of production-oriented public welfare and good ecology; accelerating the construction of a resource-saving and environmentally friendly society, and forming a modernized construction pattern of harmonious development between humans and nature.

Economic factors: A recycling-based society is an economic mode that emphasizes the harmonious development between humans and nature. It is a development that not only can meet the contemporary demands of people but also causes no harm to the life of offspring. Social and economic resources on earth are limited. People have to focus on high-efficiency use and recycling of resources. Traditional development is achieved at the expense of resource consumption and resources can only be wasted after use. Recycling economic development is an update of resource recycling technology and equipment. It changes the traditional development mode of "resource-product-waste" and establishes a recycling economic development mode of "resource-product-wasterenewable resource".

Social factors: Citizens' environmental consciousness and awareness of social responsibility in e-waste recycling have been enhanced gradually. The environmental protection industry is highly recognized in public. These conditions have brought a good opportunity for the development of the "Internet + recycling" industry. The growing consciousness of environmental protection and understanding of e-waste pollution also promotes the comprehensive implementation of e-waste recycling modes.

Technological factors: At present, four major recycling modes for e-waste are used in China. First, the repair departments of manufacturers and waste recycling stations repair, renovate, and refit e-waste and then relaunch the products on the market for secondary consumers. Second, 
disassembly workshops recycle e-waste and collect metal materials, especially precious and rare metals, through simple means for secondary marketing. Third, e-waste is sold to households in rural and poverty-stricken areas through donation or market circulation of used home appliances. Fourth, e-waste is landfilled with household waste directly. At present, e-waste output is considerable, but only a small proportion of it is recycled through standard channels. As the aforementioned four recycling modes have low technological and equipment levels and low utilization of high-quality renewable resources, e-waste causes great resource wastage and serious environmental pollution.

\section{SWOT Analysis}

Strengths: The development philosophy of the e-waste recycling industry conforms to the national development strategy. The government aims to develop a green economy as well as establish a green system and culture so that the public can benefit from green dividends. The market bidding mode based on consumer-to-business processes can help e-waste owners select the best buyer, connect the upstream and downstream of the industrial chain through timely locking, fast transaction, Internet, big data, and Internet of Things (IoT). In this manner, e-waste owners make decisions on disposal and resource value can be maximized. Based on big data analysis, idle logistics staff can be mined and matched effectively and the best transport channel can be recognized accurately the first time, thereby effectively optimizing the logistics path, decreasing the logistics marginal cost of merchants, and increasing the social employment rate. Massive information sharing is achieved and the problems of information asymmetry and few disposal channels faced by e-waste owners are solved through online registration and offline setting of fixed recycling stations. This approach increases circulation and values in the effective use of resources.

Weakness: In the early stage of "Internet + recycling," the business model of the industry was hardly accepted by merchants. Moreover, e-waste owners might not believe in this model. Thus, promoting "Internet + recycling" and establishing cooperation with merchants is a great challenge. "Internet + recycling," which uses big data, cloud computing, and IoT as the core technologies propose high requirements on the operation mode and technical personnel. It faces certain challenges in attracting talent and technological support. Information disclosure is an important problem. Many people prefer to keep their e-waste to themselves for fear of privacy exposure and even reject the "Internet + recycling" mode due to the lack of security in certain platforms.

Opportunity: The "Internet + recycling" approach is developing and penetrating into traditional industries. "Internet
+ recycling" has unique innovations and features compared with existing e-waste recycling platforms. It provides more convenient and intelligent services to both suppliers and customers and achieves a seamless connection between online and offline resources. With the rapid popularization of household appliances and digital products, product updates are accelerated and e-waste in daily life increases accordingly. In recent years, the low-carbon lifestyle has become increasingly popular and the educational background of people has improved, thereby strengthening citizen's awareness of environmental protection to a certain extent. Big data and cloud computing technologies have developed rapidly and have been applied to daily life gradually. New technologies have awakened people's curiosity and motivated them to continuously try them.

Threat: The development of a secondary recycling platform has entered a relatively stable stage. It owns a relatively mature operation mode and stable customer sources. However, most recycling platforms in China are new and inevitably affected by competitors. With the increasing attention to national policies and citizens' awareness of environmental protection and resource recycling as well as the rapid development of the Internet industry, the industrial development of the e-waste recycling market has considerable potential. This development is accompanied by a strong influx of competitors.

\section{E-WASTE CONTROL MEASURES}

\section{Perfecting Laws and Regulations on E-Waste Recycling and Disposal}

E-waste control by law is a fundamental guarantee of effective e-waste recycling and an essential way to ensure waste resource recycling. Thus, establishing and perfecting relevant laws and regulations is an essential approach to manage e-waste recycling, standardize e-waste disposal, determine the responsibilities of all parties, constrain their behaviours, and finally ensure environmental protection, resource recycling, and sustainable development. The government of China at all levels has to face up to problems in e-waste recycling, analyze the causes of these problems thoroughly, establish and integrate waste recycling systems, and determine the overall framework of e-waste recycling.

\section{Establishing and A Punitive System for E-Waste Recycling Corporate Responsibility}

With regard to the legal, regulatory and management systems for e-waste recycling and disposal in Germany and other countries in the European Union, China aims to analyze their experiences carefully and establish relevant legal 
systems according to practical situations. On the one hand, China's existing laws and regulations on e-waste recycling and disposal are mainly guidelines rather than normative documents, thereby resulting in inadequate deterrence and law enforcement as well as great difficulties in practical implementation. On the other hand, existing laws and regulations on the responsibilities of e-waste recycling are mainly in a scattered and coarse state. A suggested approach is to determine the responsibilities and duties of all parties according to legislation, determining economic incentives and punishment measures, enlisting e-waste recycling responsibilities in law-based management, and creating a good legal environment for all parties to participate in e-waste recycling positively. The problem of responsibility in e-waste recycling can be solved as long as a complete legal and regulatory system is established and perfected, thereby paving the way for follow-up responsibility practices in e-waste recycling.

\section{Strengthening Technological Support and Promotion and Education for E-Waste Recycling}

Technological support will be strengthened. E-waste recycling technologies will be evaluated in terms of environmental protection and economic efficiency. Accurate evaluations of e-waste collection, recycling, and disposal efficiencies, as well as the relevant costs or benefits, are used as the reference to improve recycling and disposal technologies. Meanwhile, the supporting information management system is established and an e-waste information platform is built to realize communication and sharing of information resources among various departments. As consumers play an important role in e-waste recycling, publicity and education are extremely important. Assisted by the Ministry of Education and the media, the government will educate the public about hazards brought by incorrect disposal of e-waste. The risks posed by e-waste to the environment and human health as well as the significance of e-waste recycling, teaching the public about e-waste recycling and harmless disposal, increasing the environmental protection consciousness of the entire society, and forming a good atmosphere for economic development. Special training on e-waste recycling will be conducted, disassembly and disposal enterprises are expected to increase the consciousness of enterprises in environmental protection through laws, and businesses will be guided toward continually improving their disposal technologies and environmental management levels.

\section{Increasing Market Supervision Efforts and Manufacturers' Consciousness of Responsibility}

Environmental protection departments in China at all levels will (1) strengthen mutual communication, increase supervision and safety monitoring means, and enhance supervision over law enforcement in the e-waste recycling industry; (2) establish an examination and verification system for e-waste disposal enterprises, insist on eliminating and banning backward disposal facilities and abilities with serious pollution, suspend facilities with e-waste handling capacity that is much less than the declared capacity unless the desired handling capacity is reached; and (3) strengthen supervision and examination in regions with prominent e-waste environmental pollution, and impose a penalty on enterprises for falsification, environmental pollution, and violations against laws and regulations, as well as restrict the participation of these enterprises in relevant e-waste disposal activities for a certain period. Manufacturers are asked to assume corresponding responsibilities in e-waste recycling and establish internal management files for e-waste during the production process. E-product manufacturers are encouraged to set up a recycling and disposal system or authorize a qualified unit for disassembly if they cannot perform these tasks.

\section{CONCLUSIONS}

waste can bring serious damage to soil, water sources, air, and human health. With the massive growth of the e-industry and progress of e-technologies, a great deal of e-products are consumed every year. E-waste, such as battery and heavy metals, causes various environmental damage on non-standard recycling and disposal although the industry brings considerable profits to the state. In this study, research on e-waste recycling modes and control measures in foreign developed countries were first reviewed. Second, the e-waste recycling mode in China was analysed through the PEST and SWOT models by combining practical situations in the country. Third, e-waste control measures were proposed from various perspectives. Results show that environmental pollution caused by e-waste in China were manifested in three aspects, such as serious ecological environmental pollution, considerable natural resource waste, and frequent occurrence of social crises. The PEST and SWOT models conformed to the characteristics of macroscopic management in China. Both the PEST and SWOT analysis results showed that the e-waste recycling mode in China was equipped with a good policy space. Finally, specific e-waste control measures were proposed, including perfecting laws and regulations on recycling and disposal; establishing a punitive system for e-waste recycling corporate responsibility; strengthening technological support, promotion, and education related to e-waste recycling; and increasing the market supervision efforts and manufacturers' consciousness of responsibility. Further studies on intelligent e-waste control based on the cooperation game model among the government, 
manufacturing enterprises, and third-party professional recycling enterprises; measurement of influencing factors in consumers' intention to recycle e-waste; as well as incentive policies for recycling enterprises, cloud computing, and big data can be conducted in the future.

\section{ACKNOWLEDGMENT}

This work was supported by the Young Core Teacher Training Plan of Henan Provincial Higher Vocational School (2019GZGG018) and the 2019 Young Core Teacher Training Plan of Henan Industrial Vocational and Technical College.

\section{REFERENCES}

Aboelmaged, M. 2021. E-waste recycling behaviour: An integration of recycling habits into the theory of planned behaviour. Journal of Cleaner Production, 278: 124182.

Allenby, B., Williams, E., Kim, J., Kahhat, R., Ming, X. and Peng, Z. 2008. Exploring e-waste management systems in the United States. Resources Conservation \& Recycling, 52(7): 955-964.

Atasu, A., Gui, L., Özlem Ergun and Toktay, L.B. 2013. Implementing extended producer responsibility legislation: a multi-stakeholder case analysis. Journal of Industrial Ecology, 17(2): 262-276.

Bernardes, A. M., Dias, P. and Huda, N. 2019. Ensuring best e-waste recycling practices in developed countries: An Australian example. Journal of Cleaner Production, 209(1): 846-854.

Chen, S. J., Luo, X., Mai, B., Ma, Y. J., Tian, M. and Wang, J. 2010. Brominated flame retardants in house dust from e-waste recycling and urban areas in South China: Implications on human exposure. Environment International, 36(6): 535-541.
Chen, X. W., Deng, W. J., Giesy, J. P., Li, N. and Zheng, H. L. 2018. PBDEs and Dechlorane Plus in the environment of Guiyu, Southeast China: A historical location for E-waste recycling $(2004,2014)$. Chemosphere, 199(May): 603-611.

Cheung, K. C., Duzgoren-Aydin, N. S., Leung, A. O. W. and Wong, M. H. 2008. Heavy metals concentrations of surface dust from e-waste recycling and its human health implications in southeast China. Environmental Science \& Technology, 42(7): 2674-80.

Covaci, A., Tang, B., Poma, G., Cuykx, M., Luo, X. J. and Liu, Y. 2018. Occurrence of organophosphorus flame retardants and plasticizers in wild insects from a former e-waste recycling site in the Guangdong province, South China. The Science of the Total Environment, 650(1): 709-712.

Halluite, J. A., Linton, J. D. B. E., Yeomans, J. S. C. and Yoogalingam, R. 2012. The challenge of hazardous waste management in a sustainable environment: Insights from electronic recovery laws. Eco-Management and Auditing, 12(1): 31-37.

Lang, H., Qin, Y., Xu, M., Han, Y., Ye, W. and Zhang, S. 2019. Emission reduction benefits and efficiency of e-waste recycling in China. Waste Management, 102: 541-549.

Liu, Matsui, Y. X. and Tanaka, M. 2006. Electrical and electronic waste management in China: Progress and the barriers to overcome. Waste Management \& Research Journal of the International Solid Wastes \& Public Cleansing Association Iswa, 24(1): 92-101.

Lu, B., Xu, C. and Yang, J 2008. WEEE flow and mitigating measures in China - Science Direct. Waste Management, 28(9): 1589-1597.

Mor, S. and Ravindra, K. 2019. E-waste generation and management practices in Chandigarh, India and economic evaluation for sustainable recycling. Journal of Cleaner Production, 221(June 1): 286-294.

Ru, Y. H., Veenstra, A., Wang, R.J., Wang, Y. and Wang, Y. C. 2010. Recent developments in waste electrical and electronics equipment legislation in China. International Journal of Advanced Manufacturing Technology, 47(5): 437-448.

Tian, F., Xue, R. and Zhang, F. 2018. A system dynamics model to evaluate effects of retailer-led recycling based on dual chains competition: A case of e-waste in China. Sustainability, 10(10): 3391. 